\title{
Exploring and Developing the Scale of Vocational High School Teachers' Work Stress and Coping Strategies under the Trend of Fewer Children
}

\author{
Yi-Chen Chang, Chin-Wen Liao, Yao-Tsung Chiang, and Chia-Ling Shih
}

\begin{abstract}
This study aimed to develop the cognition scale of "Vocational High School Teachers' Work Stress and Coping Strategies under the Trend of Fewer Children". This study was approved by literary reviews and its research framework to compile the research tools. The opinions provided from the experts and scholars in related fields of technic vocation education and the teacher representatives of vocational high school of continuing education in groups of electric machinery and electron, which as the content validity of research tools. This study using the principle of purposive sampling to select the pilot test subjects for this study, to pick 9 vocational schools and sent 124 questionnaires, 102 valid questionnaires retrieves to implement pilot test. The retrieved pilot test questionnaires was carry out constructs analysis, factor analysis and Cronbach $\alpha$ coefficient test by statistical software, and examined the level of questionnaires' validity and reliability. The internal consistency of reliability coefficient is quite well to questionnaire subscales and the overall scale.
\end{abstract}

Index Terms-Fewer children, coping strategies, teachers' work stress, vocational high school teachers.

\section{INTRODUCTION}

\section{A. Research Background and Motivation}

The education has changed rapidly as well as society in recent years. According to Department of Household Registration of Ministry of the Interior [1] statistics, the newborns numbers in Taiwan has declined continuously from a peak of 424,250 in 1963 to 166,886 in 2010, reduction of neonates numbers are confronted by many countries. According to 2011 World Population Overview table pointed out that many highly advanced and developed countries where fertility is too low, and even the global population growth rate has fallen [2]. The term of "Fewer Children Society "are firstly shown and defined on "Fewer Children Society White Paper "which compiled by The Cabinet Office, Government of Japan[3]. More simply put, the circumstance of inefficient neonate's numbers causes the symptom of population negative growth, which are called "Population of Fewer Children" [4]. In the 2010 academic year, there are 42969 registered vocational high school and general high school teachers nationwide. The number will drop to 22027 in 15 years in accordance with the current births numbers, about 5,506 vocational high school teachers among them,

Manuscript received March 8, 2014; revised May 10, 2014.

The authors are with the Department of Industrial Education and Technology at National Changhua University of Education (NCUE), Taiwan (e-mail: yd3174@gmail.com, tcwliao@cc.ncue.edu.tw, cytsung@gmail.com, malisa168@yahoo.com.tw). indicating an approximate reduction $40 \%$ in the number of vocational high school teachers. Accordingly the theme of exploration is education staff work stress under the impact from fewer children. Women of childbearing age in Taiwan total fertility rate is less than 1 person today, meaning the decrease of women fertility desire. Most parents chose to bear one children merely. The condition of fewer children resulted in the increase tendency of elementary school singleton student [5]. In addition, due to the fewer children, changes in parents discipline to their children, parents centralize more care and protection to the singleton in family [6]. Yet the lack of interacting are associated with some learning issues, with classmate as well as siblings in terms of competition and cooperation, making these singletons vulnerable at school community. What strategies teachers cope with [7]? Parents expect their children will have a bright future, hoping teacher pay more attention on their children without considering the rights of other students. While spending more energy to communicate with parents, teachers also have to pay attention on certain students. This can be a source of stress on teachers [8].

Yet with fewer children, school administrative work remains the same, and many teachers have to take consequently part-time administrative work due to reduced teacher posts. It is therefore possible that the fewer children trend can add more burdens to teachers' workload. Although there are many literatures investigated work stress of teachers, few of those explored vocational high school teachers' work stress under the trend of fewer children, and filling such a gap is one of the research motivations here.

Stress at work in the context of modern life is inevitably part of it. Proper working stress stimulus can arouse challenge motive and help improve work performance for individuals as well, but if the stress exceeds a certain level, people will feel frustrated and result in lower job performance.

The essence of the profession of teachers is different from of others in society, Aside from heavy teaching responsibilities, teachers are daily challenged by countless problems from students, assignment marking, participating in a variety of teaching or activities, or part-time administrative work, etc.; in addition, because of pursuing higher education, teachers also experience more pressure from the society as well as parents. Excluding the factors of school administrative work, workload, student problems, interpersonal relationship etc., what others will cause teachers' work stress? Reference [9] pointed out the teacher's work stress resource comprehend five dimensions: "Teaching Load", "Student Performance", "Administration 
Support", "Specialty Promotion", "Interpersonal relationships", etc. How teachers tackle and decrease work stress? As the role of teacher, improper dealing with the work stress from student problems and interpersonal relationship, resulting in the adverse demonstration of teaching is bound to affect the student personality and education.

In view of aforesaid indicating reasons, it is necessary to deeply explore " Vocational High School Teachers' Work Stress and Coping Strategies under the Trend of Fewer Children ", hoping to develop the empirical research scale, furthermore, to offer reference to whom may concern or units in relation to this issue, which become the second research motivation.

\section{B. Research Objects}

This study aimed to develop the cognition scale of "Vocational High School Teachers' Work Stress and Coping Strategies under the Trend of Fewer Children". According to research background and motivation described above, the purpose of this study are as follows:

To develop the scale of "Vocational High School Teachers' Work Stress and Coping Strategies under the Trend of Fewer Children".

\section{RESEARCH DESIGN AND IMPLEMENTATION}

The study used the questionnaire survey method. For achieving the purpose, collecting related information from the course of literary reviews, then based on this study research framework to modify and compile the questionnaires of "Vocational High School Teachers' Work Stress and Coping Strategies under the Trend of Fewer Children ", and research tools for this study as well.

This study questionnaires used Likert five-point scale, in compliance with this study objects, probing into vocational high school teacher" "Work stress " and " Coping strategies " in two sections under the trend of fewer children. Tested subjects are in conformity with the specification of each question, and 5 items of "Strongly agree, Agree, Neutral, Disagree, Strongly disagree" from the scale, selecting the most similar and suitable items, as close with the feeling oneself. The scoring rule stipulated "Strongly agree" for 5 points, "Agree" for 4 points, "Neutral" for 3 points, "Disagree "for 2 points, "Strongly disagree" for 1 point. The higher points which respondents obtained from the scale in the "Work Stress survey "questionnaire, the higher degree that the tested subjects experienced from "Vocational High School Teacher' Work Stress “. As to "Coping Strategies "survey questionnaire is to react to the identification of respondents on this topic. The respondents obtained higher points in the scale, meanning they are bound for more positive attitude of vocational high school teacher' coping strategies.

Herewith specifying the process of research tools for this study as bellows:

\section{A. Compiling Framework and the First Draft of Questionnaire}

For objectivity analysis of " Vocational High School Teachers' Work Stress and Coping Strategies under the
Trend of Fewer Children ", Literature reviews became the theory foundation of this study, developing the first questionnaire draft. Content of questionnaire divided into three parts. The first part is the basic data of respondents. There are total 35 questions of the second part is the survey of "Vocational High School Teachers' Work Stress under the Trend of Fewer Children", which comprises 5 constructs are "Work load, Professional knowledge and skills, Interpersonal relationships, Decisions for current situations, Teaching counseling "etc., and total 19 questions of the third part is the survey of "Vocational High School Teachers' Coping Strategies under the Trend of Fewer Children", containing 4 constructs are "Problem solving, Procrastination in processing, Seeking for help, Emotional adjustment", etc. The sum of 54 questions is for above.

TABLE I: THE CONSTRUCTS OF "VOCATIONAL High SCHOOL TEACHERS' WORK STRESS AND COPIN STRATEGIES UNDER THE TREND OF FEWER CHILDREN"

\begin{tabular}{|c|c|c|c|}
\hline & Factor / Construct & of $C$ & ubtotal \\
\hline \multirow{5}{*}{$\begin{array}{l}\text { Vocational high } \\
\text { school teachers' } \\
\text { work stress } \\
\text { under the trend of } \\
\text { fewer children }\end{array}$} & Work load & 5 & \multirow{5}{*}{35} \\
\hline & $\begin{array}{c}\text { Professional } \\
\text { Knowledge } \\
\text { and skills } \\
\end{array}$ & 8 & \\
\hline & $\begin{array}{l}\text { Interpersonal } \\
\text { relationships }\end{array}$ & 10 & \\
\hline & $\begin{array}{c}\text { Decisions for } \\
\text { current situations }\end{array}$ & 4 & \\
\hline & $\begin{array}{c}\text { Eaching } \\
\text { counseling }\end{array}$ & 8 & \\
\hline \multirow{5}{*}{$\begin{array}{l}\text { Vocational high } \\
\text { School teachers' } \\
\text { coping strategies } \\
\text { of work stress unde } \\
\text { the trend of fewer } \\
\text { children }\end{array}$} & $\begin{array}{c}\text { Problem } \\
\text { solving }\end{array}$ & 6 & \multirow{4}{*}{19} \\
\hline & $\begin{array}{l}\text { Procrastination } \\
\text { in processing }\end{array}$ & 4 & \\
\hline & $\begin{array}{l}\text { Seeking } \\
\text { for help }\end{array}$ & 5 & \\
\hline & $\begin{array}{l}\text { Emotional } \\
\text { adjustment }\end{array}$ & 4 & \\
\hline & \multicolumn{2}{|l|}{ Total } & 54 \\
\hline
\end{tabular}

\section{B. Establishing Professional Contents Validity}

After the first draft of this study questionnaires were accomplished, and being revised through adviser. The opinions were utilized as amendments for of title, text, words, etc. of the questionnaire to establish the important reference to modify formal questionnaire, as well as the content validity of research tools for this study, which provided from the experts and scholars and the teacher representatives of vocational high school in groups of electric machinery and electron, who were in accordance with the questions appropriateness to examined questions in turn, chosen one of options consisted of " appropriate, delete, revision " under each question's items, writing down revision comments in comment column if questionnaire content need to be revised, compiling pilot test questionnaires through retrieving and processing.

\section{Pilot Test of Research Tools Implementation}

For understanding the appropriateness and feasibility of the questionnaires, which carried out instantly pilot test after 
the first questionnaires draft were accomplished. Pilot test questionnaires were mailed starting from May 2012, using the principle of purposive sampling to select the pilot test subjects of this study, to pick 9 vocational schools and sent 124 pilot test questionnaires, resulting in a volume of 102 valid questionnaires retrieved, and $82 \%$ of percentage of valid questionnaires retrieved.

\section{ANALYSIS AND DiSCUSSION OF RESEARCH RESUlTS}

For obtaining more rigorous framework validity and reliability of this research tool, the retrieved pilot test questionnaires was carry out program analysis, factor analysis and Cronbach $\alpha$ coefficient test by statistical software, examining the level of questionnaire validity and reliability, further, which as the reference of the formal questionnaires' questions, specification as bellows :

\section{A. Constructs Analysis}

There are 35 questions and 5 constructs in " Teachers' Work Stress" survey questionnaire, in the order of "Workload", "Professional knowledge and skills", "Interpersonal relationships ", " Decisions for current situations", " Teaching counseling ". Through the SPSS statistical analysis, as the CR value results of 11.527 5.775 was significantly, the result of 0.061 for the 21 th question was insignificantly alone. According to the aforesaid deleting questions rule, of which the 21th question after been deleted, the Cronbach's $\alpha$ value is greater than Cronbach's $\alpha$ value of the total scale. The $\alpha$ value of total scale was 0.972 before the question undeleted ( $\alpha$ value was 0.975 after the question deleted), therefore deleting this one, and the rest remained.

There are 19 questions with 4 constructs in "Teachers' coping strategies under work stress" survey questionnaire, in the order of "Problem solving", "Procrastination in processing", "Seeking for help", "Emotional adjustment ". Through the SPSS statistical analysis, as the CR value results of 3.156 8.642 was significantly, the result of 1.307 for the 10th question was insignificantly alone. According to the aforesaid deleting questions rule, of which the 10th question after been deleted, the Cronbach's $\alpha$ value is greater than Cronbach's $\alpha$ value of the total scale. The $\alpha$ value of total scale was 0.865 before the question undeleted ( $\alpha$ value was 0.876 after the question deleted), therefore deleting this one, and the rest remained.

\section{B. Factor Analysis}

TABLE II: KMO INDICATOR AND BARTLETT TEST RESULTS ON "TEACHERS' WORK STRESS" SURVEY QUESTIONNAIRE

\begin{tabular}{ccc}
$\begin{array}{c}\text { Kaiser-Meyer-Olkin measure of sampling } \\
\text { adequacy }\end{array}$ & & .929 \\
\hline Bartlett's sphericity test & Approx. & 3169.27 \\
& Chi-square & 2 \\
\hline df & 561 \\
\hline & Sig. & .000 \\
\hline
\end{tabular}

$N=102$

After the 21th question deleted of "Teachers' Work Stress" survey questionnaire in this study pilot test questionnaires, factor analysis KMO indicator was .929 , which was suitable for factor analysis, X2 of "Bartlett test result" was 3169.272 (df 561) significantly, meanning common factors existed in correlation matrix of populations, this questionnaire was suitable to implement factor analysis, the results are shown in Table II.

Deleting the 10th question of "Teachers' Coping Strategies of Work Stress" survey questionnaire in this study pilot test questionnaires, factor analysis KMO indicator was .811, which was suitable for factor analysis, X2 of "Bartlett test result" was 872.759 (df 153) significantly, indicating common factors existed in correlation matrix of populations, this questionnaire was suitable to implement factor analysis, the results are shown in Table III.

TABLE III: KMO INDICATOR AND BARTLETT TEST RESULTS ON "TEACHERS' COPING STRATEGIES OF WORK STRESS" SURVEY QUESTIONNAIRE

Kaiser-Meyer-Olkin

measure of sampling adequacy

\begin{tabular}{ccc}
\hline Bartlett's sphericity test & $\begin{array}{c}\text { Approx. } \\
\text { Chi-square }\end{array}$ & 872.759 \\
\hline df & 153 \\
\hline Sig. & .000 \\
\hline
\end{tabular}

$N=102$

TABLE IV: RELIABILITY ANALYSIS ABSTRACT OF "VOCATIONAL HIGH SCHOOL TEACHERS WORK STRESS" SURVEY QUESTIONNAIRE

\begin{tabular}{|c|c|c|c|c|}
\hline No. & Factors & $\begin{array}{c}\text { Number } \\
\text { of } \\
\text { Question }\end{array}$ & $\begin{array}{c}\text { Cronbach's } \\
\alpha \text { value of } \\
\text { construct } \\
\text { factors }\end{array}$ & $\begin{array}{c}\text { Overall } \\
\text { scale } \\
\text { Cronbach's } \\
\alpha \\
\end{array}$ \\
\hline Factor 1 & Workload & 6 & .872 & \\
\hline Factor 2 & $\begin{array}{c}\text { Professional } \\
\text { knowledge } \\
\text { and skills }\end{array}$ & 3 & .847 & \\
\hline Factor 3 & $\begin{array}{l}\text { Interpersonal } \\
\text { relationships }\end{array}$ & 8 & .932 & .975 \\
\hline Factor 4 & $\begin{array}{c}\text { Decisions } \\
\text { for current } \\
\text { situations } \\
\end{array}$ & 7 & .915 & \\
\hline Factor 5 & $\begin{array}{l}\text { Teaching } \\
\text { counseling }\end{array}$ & 10 & .950 & \\
\hline
\end{tabular}

Five factors in "Vocational High School Teachers' Work Stress " survey questionnaire were extracted, which eigenvalue were $6.020,5.994,4.923,4.100$ and 3.477 respectively, the eigenvalues greater, indicating the more important that the factors in explaining the structure of variables, which variance explained were $17.707 \%, 17.630 \%$, $14.481 \%, 12.059 \%$ and $10.227 \%$. The factor loading of Factor 1. was 0.428 0.687, Factor 2. was 0.527 0.784, Factor 3. was 0.516 0.773, Factor 4. was 0.429 0.729, Factor 5. was 0.541 0.699, the cumulative veriance explained was $72.103 \%$, thus there are 5 available factors to explain the cumulative veriance of $72.103 \%$.

Taking four factors from "Vocational high school teacher coping strategies under work stress" survey questionnaire, which eigenvalue were $3.278,3.051,2.804$ and 2.393 respectively, which variance explained were $18.214 \%, 16.953 \%, 15.576 \%$ and $13.296 \%$. The factor loading of Factor 1. was 0.432 0.812, Factor 2. was $0.585 \sim 0.817$, Factor 3. was 0.654 0.881, Factor 4. was $0.725 \sim 0.852$, the cumulative variance explained was $64.038 \%$, thus there are 4 available factors to explain the cumulative variance of $64.038 \%$. 


\section{Reliability Analysis}

The pilot test questionnaires implemented analysis of item, factor and reliability, as could understood the dependability of questionnaires. This study adopted Cronbach's $\alpha$ coefficient to examine the scale internal consistency.

For "Vocational High School Teachers Work Stress" survey questionnaire, overall scale $\alpha$ coefficient was 0.975 , internal consistency $\alpha$ coefficients of five subscales were 0.872, 0.847, 0.932, 0.915,0.950, as shown in Table IV.

For "Vocational High School Teachers' Coping Strategies of Work Stress" survey questionnaire, overall scale $\alpha$ coefficient was 0.816 , internal consistency $\alpha$ coefficients of four subscales were $0.829,0.789,0.805$ and 0.813 , as shown in Table V, all $\alpha$ coefficients of subscales and overall scales are 0.70 up. The internal consistency is quite well obviously to questionnaire subscales and the overall scale after questions deleted.

TABLE V: RELIABILITY ANALYSIS ABSTRACT OF "VOCATIONAL HiGH SCHOOL TEACHERS' COPING STRATEGIES OF WORK STRESS” SURVEY QUESTIONNAIRE

\begin{tabular}{|c|c|c|c|c|}
\hline No. & Factors & $\begin{array}{c}\text { Number } \\
\text { of } \\
\text { Question }\end{array}$ & $\begin{array}{c}\text { Cronbach's } \alpha \\
\text { value of } \\
\text { construct } \\
\text { factors }\end{array}$ & $\begin{array}{c}\text { Overall } \\
\text { scale } \\
\text { Cronbach's } \\
\alpha\end{array}$ \\
\hline $\begin{array}{c}\text { Factor } \\
1\end{array}$ & Problem solving & 5 & .829 & \\
\hline $\begin{array}{l}\text { Factor } \\
2\end{array}$ & $\begin{array}{l}\text { Procrastination } \\
\text { in processing }\end{array}$ & 3 & .789 & .876 \\
\hline $\begin{array}{l}\text { Factor } \\
3\end{array}$ & $\begin{array}{l}\text { Emotional } \\
\text { adjustment }\end{array}$ & 4 & .805 & \\
\hline $\begin{array}{c}\text { Factor } \\
4\end{array}$ & Seeking for help & 6 & .813 & \\
\hline
\end{tabular}

\section{Formal Questionnaires}

Experts and scholars provided revision comment for modifying the pilot test questionnaires, thereupon improper questions deleted to compile formal questionnaires after analysis of item, factor and reliability etc.

Formal questionnaires' content divided into four parts. The first part is the basic data of respondents. The second part is the "Vocational High School Teachers' Work Stress "survey questionnaire, comprising 5 constructs are "Work load, Professional knowledge and skills, Interpersonal relationships, Decisions for current situations, Teaching counseling" etc., and the total of 35 questions. The third part is the of "Vocational High School Teachers' Coping Strategies of Work Stress "survey questionnaires, which contains 4 constructs are" Problem solving, Procrastination in processing, Seeking for help, Emotional adjustment", etc., and the sum of 19 questions.

\section{CONCLUSIONS}

According to research results and objects, this study proposes important conclusions as follows:

To develop the scale of "Vocational High School Teacher' Teaching Persecution and Coping Strategies under the Trend

\section{of Fewer Children".}

1) This study comprise nine personal background variables, which are Gender, Age, Marital Status, Teaching Seniority, Teaching Seniority at Present School, Education Background, Expertise in Counseling or Special Education, Number of Classes for the Responsible Subject, and School Region etc.

2) The dependent variables of "Vocation High School Teachers' Work Stress under the Trend of Fewer Children "were divided into five types of Workload, Professional Knowledge and Skills, Interpersonal Relationship, Decisions for Current Situations, and Teaching Counseling etc. " Vocation High School Teachers' Coping Strategies under the Trend of Fewer Children ", which dependent variables were divided into four types of Problem Solving, Postponing and Escaping, Seeking for Help, and Emotional Adjustment etc. The scales of this study were empirically verified through pilot test, as have sufficient confidence in reliability and validity.

\section{REFERENCES}

[1] Household Registration Office of Ministry of the Interior. (2010). Vital statistic for a hundred years. [Online]. Available: http://www.ris.gov.tw/ch4/static/Centennial population data.xls

[2] Council for Economic Planning and Development. (2011). World Population Summary. [Online]. Available: http://www.cepd.gov.tw/dn.aspx?uid=10425

[3] J. M. Chen, "The study of the affection of fewer children phenomenon to school operation for Junior High School in Taipei," Master Thesis, Master Degree Class for In-service, Department of Education, National Taiwan Normal University, 2008.

[4] C. Z. Wu, "The study of organization reform strategies of coping fewer children for elementary schools in Kaohsiung City, Taiwan," Master Thesis, Graduate Institutes of Adult Education, National Kaohsiung Normal University. Unpublished, Taipei, 2008.

[5] L. C. Yuan, "The related study of gender, grade, dependency relationship and life accommodation of primary school singleton student - cited example of Tainan City," Master Thesis, Master Degree Class of Tutoring Teaching for Teacher In-Service Education, National University of Tainan. Unpublished, Tainan, 2002.

[6] Y. C. Lu and F. Y. Wang, "A brief introduction on influences from parental expectation on only children," Journal of Family Education Bimonthly, vol. 29, pp. 14-29, 2011.

[7] M. Q. Zhang, "The relationship among parental raising attitude intrapersonal intelligence and interpersonal intelligence between students from a single-child family and a multiple-children family," Master Thesis, Department of Psychology and Counseling, Taipei Municipal University of Education. National Digital Library of Theses and Dissertations in Taiwan, 2009.

[8] Y. H. Chen, "Who has depleted the passion of teacher?" Education, Parenting, Family Lifestyle, vol. 16, 2010.

[9] M. Y. Shu, "The Investigation of teacher's work stress of awareness and emotion management for primary school teachers in Penghu County," Master thesis, Department of Educational Management, National Taipei University. Unpublished, Penghu County, 2011.

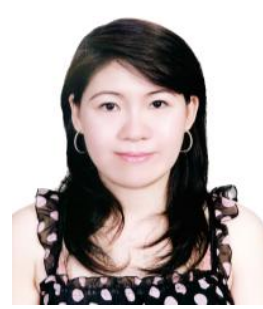

Yi-Chen Chang received M.S. in Graduate Institute of Technology and Vocational Education National Taipei University of Technology in 2009, and is studying Ph.D. in Department of Industrial Education and Technology at National Changhua University of Education (NCUE) in Taiwan, R.O.C. respectively. Since August 2008, she served the position as the director in Department of Fashion and Styling Design at Chungyu Institute of Technology in Taiwan, R.O.C. She is the director of Department of Fashion and Styling Design at Yuda University of Science and Technology from 2011 until now. She teaches courses in hairdressing and cosmetology. Her research interest is technology and vocational education. 


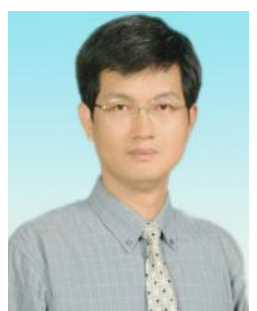

Chin-Wen Liao received his M.S. and Ph.D. degree in industrial education from National Taiwan Normal University, Taiwan, R.O.C. in 1994 and 2002 respectively. Since August 2011, he has been a professor in Department of Industrial Education and Technology at National Changhua University of Education (NCUE) in Taiwan, R.O.C. He teaches courses in technology and vocational education, energy education, course and teaching, organizational learning. His research interests include technology and vocational education, teacher education, energy education of technology, and learning organization.

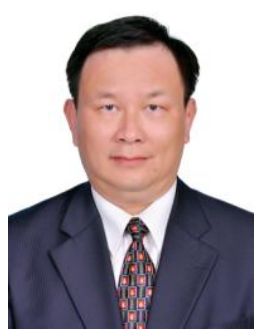

Yao-Tsung Chiang received M.S. degree in agricultural machinery engineering from National Chung Hsing University in 2002, and currently is a doctoral student of the Department of Industrial Education and Technology at National Changhua University of Education (NCUE). Since August 2009, he had been the principal of National Chia-Yi Industrial Vocational High School until 2013, then transferred to be the principal of National Wufeng Agricultural and Industrial Vocational High School.
Since August 1984, he has taught courses in agricultural machinery, mechanical drawing, introduction of computer science, frozen food machinery and introduction of machinery in National Yuanlin Agricultural and Industrial Vocational High School until 2009.

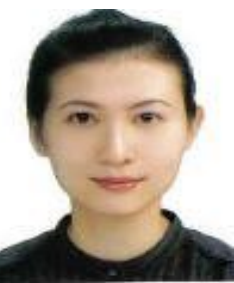

Chia-Ling Shih now is teaching in Ingdao High School in Taichung city, Taiwan and studying in tourism who graduated in EMBA from Providence University in 2012 